\title{
Psychological Contributors to the Failure to Anticipate Unintended Consequences
}

\author{
Erin Sparks and Joyce Ehrlinger* \\ Florida State University
}

\begin{abstract}
History is replete with well-intentioned actions and policies that have resulted in dramatic unintended consequences. We review evidence that several psychological biases result in an overly narrow focus on the intended consequences of acts and, consequently, tendencies to ignore or give too little weight to potential unintended consequences. First, a motivated desire for the intended consequences of acts can blind people to the likelihood of alternative possibilities. We review evidence that people process information and evidence in biased ways, leaving them overconfident that the desired consequences will come to pass. Second, even in the absence of motives regarding potential consequences, biases in cognition lead people to focus their attention narrowly on intended consequences in a way that limits their consideration of important alternative, unintended consequences. We review how biases toward focalism and anchoring contribute to a failure to foresee unintended consequences. Finally, we review evidence that subtle manipulations of both motivation and attention can be used to increase the focus and weight given to potential unintended consequences and, consequently, improve anticipation.
\end{abstract}

Throughout history, well-intentioned actions have often led to unintended and unforeseen consequences. For example, in 1920, policy makers passed National Prohibition, a ban on the sale, manufacture, and transportation of alcohol in the United States, in hopes of reducing negative health and social consequences related to the sale and use of alcohol. The actual consequences of prohibition, however, were quite different than what was intended. People turned to medicinal alcohol that was legal but also more potent than other forms of alcohol. As a result, deaths by alcohol poisoning increased by 300\% (Thornton, 1998). The Civil Rights Act of 1991 also led to unforeseen negative consequences that were quite the opposite of what was intended. This Act was designed to minimize discrimination in the workplace by increasing the legal rights of plaintiffs. Instead, it increased employers' fear of legal action and made them less likely to hire minority applicants than they had been before the Act was passed (Oyer \& Schaeffer, 2003).

While striking examples such as these serve as salient reminders that policies do not always have the consequences that were intended, it can be extremely challenging to foresee potential unintended consequences. Across disciplinary lines researchers have sought to identify and understand the unintended consequences that do occur and, importantly, to improve people's ability to anticipate unintended consequences. This literature includes in depth analyses of specific policies and acts that have resulted in unintended consequences, including unintended consequences in organizations (e.g., Kaminski, 2001; McBriarty, 1988; Wilson, Hickson, \& Miller, 1999), political systems (Levine, 1980; Sarason, 1978; Thornton, 1998), medicine (Fisher \& Welch, 1999), technology (Reason, 1987), and social systems (Gulas \& McKeage, 2000; Kipnis, 1993; 
Meddin, 1986; Opp, 2002). These analyses are enormously valuable and likely inform decisions regarding what policy or strategy is best pursued in the future. However, they do not always offer generalizable lessons regarding how to better foresee unintended consequences for future actions or policies.

Far less attention has been paid to potential psychological sources of the failure to anticipate unintended consequences. We think this an important area of research focus. To the degree that people better understand the psychological factors that impede anticipation of unintended consequences, they might better understand how to improve prediction. In the present paper, we review several psychological biases that serve to narrow people's focus to the intended consequences of actions and lead to a neglect of potential unintended consequences. First, we describe how a desire to see the intended consequence might lead people to evaluate information in biased ways and to neglect the potential for consequences other than what is intended. In a second section, we review evidence that cognitive tendencies to focus on a narrow subset of available information and to engage in biased hypothesis testing lead people to neglect the potential for important, unintended consequences even in the absence of a desire for a particular outcome. Finally, we use this framework to propose subtle manipulations of motivation and focus that could improve the ability to anticipate unintended consequences.

This analysis draws upon research regarding predictions of consequences for individual actions as well as consequences for large-scale policy decisions. We suspect that similar biases cloud the ability to foresee unintended consequences of one's own actions as for the actions taken by another person or group. That said, perhaps the most interesting and important examples of unintended consequences stem from policy decisions and, as such, we focus much of our discussion on anticipating the unintended consequences of policies.

\section{Motivated Bias and the Failure to Anticipate}

One salient psychological roadblock for anticipating unintended consequences of policies is that people are often motivated to believe that the policies they support will lead to intended consequences and that they will not result in negative, unintended consequences. People tend to engage in "motivated reasoning" to support these beliefs, characterized by a tendency to readily accept information and conclusions consistent with one's preferences while resisting information and conclusions inconsistent with preferences (for a review, see Gilovich, 1991; Kunda, 1990). We expect that people engage in motivated reasoning to support their beliefs that the intended consequences of policies that they support will occur. As a result, we suggest that they will give too little attention and demonstrate too much resistance to the possibility that alternative and, in particular, negative consequences might occur instead.

For example, people might be particularly willing to believe that any policy proposed by someone on their side of the political spectrum is likely to have positive intended consequences. Indeed, people's attitudes toward policies are strongly predicted by whether the policy has been proposed by someone who shares their political party or someone from an opposing party (Cohen, 2003). This effect of group is stronger than the effect of the actual content of the policy or of people's own political attitudes. Not surprisingly then, people's expectations regarding the consequences of policies are often divided on party lines. Consider, for example, differences between Republicans and Democrats in their beliefs about the plan for national healthcare proposed by President Obama in 2009. Democrats were, of course, more favorable toward the proposal than 
Republicans. But the groups also differed in their beliefs about how this proposal for healthcare would impact the healthcare decisions of everyday Americans. In one 2009 survey of public opinion, $84 \%$ of Republicans reported a belief that the proposed plan for national healthcare would result in so-called "death panels" in which bureaucrats would decide on a case by case basis whether elderly Americans would be allowed expensive medical procedures. In comparison, only $15 \%$ of Democrats polled believed that the proposed healthcare plan would lead to this unintended consequence (Nyhan, 2010).

One way in which motivation might impact people's beliefs about the consequences of policies is to narrow people's focus on preference-consistent information during the initial stages of hypothesis and theory generation. People tend to generate theories about how the world works that are self-serving, while neglecting to consider or generate theories that are less personally desirable (Kunda, 1987, 1990). We argue that the motivation to believe that the intended consequence is most likely can lead people to focus most of their thinking on that intended consequence. As a result, they might not consider potential unintended consequences that could result from the same action. In the above example, supporters of Obama might less often focus their attention on the possibility that his healthcare plan could result in unintended consequences, compared to those less supportive of Obama. Instead, supporters of Obama might focus most of their thoughts about the healthcare proposal on the potential positive intended consequences of the proposed plan.

People also treat new information differently, depending on whether that information is consistent with a preferred belief. Ditto, Scepansky, Munro, Apanovitch, and Lockhart (1998) suggested that preference-inconsistent information produces a more detailoriented state of mind than preference-consistent information. Unfavorable information inspires negative emotions, which are known to produce in-depth, systematic cognitive processing in order to facilitate the immediate behavioral actions that negative events normally require (Pratto \& John, 1991; Taylor, 1991). Thus, evidence supporting an undesirable conclusion will be processed in an in-depth, critical manner and only accepted when the quality of the evidence withstands intense objective scrutiny. Preference-consistent information tends to be accepted uncritically with little regard for information quality (Ditto, Scepansky, Munro, Apanovitch, \& Lockhart, 1998; Lord, Ross, \& Lepper, 1979).

For example, in one study, Ditto et al. found that participants were equally willing to accept an unfavorable versus favorable medical test result when the test was described as very reliable, because the unfavorable results held up under careful scrutiny. However, when the test was described as unreliable, participants continued to uncritically accept the favorable results while doubting the unfavorable results. In a similar way, people might readily accept information suggesting that a policy they support will lead to its intended consequence, while rejecting information contrary to that preferred conclusion.

Last, motivation can cause people to selectively access information from their memories in a way that allows them to maintain self-serving beliefs (Kunda, 1987, 1990). For example, participants who were led to believe that extroversion increased the likelihood of academic success recalled memories of having been extroverted in the past more quickly than participants led to believe that extroversion led to less academic success (Sanitioso, Kunda, \& Fong, 1990). Thus, people remember preference-consistent information more quickly than unfavorable information. People also remember more information consistent with favored beliefs than unfavored beliefs. For example, Ross, McFarland, and Fletcher (1981) found that participants led to believe that brushing their teeth was bad for their health remembered having brushed their teeth less often than those told it was beneficial for their health. 
This work has important implications in the domain of policy because people's expectations for the future are informed by their memories of the past. For example, someone who supports gun control might more readily recall examples suggesting that gun control laws lead to less crime and a safer society than someone who opposes gun control. In contrast, the gun control opponent might more readily recall examples that suggest gun control is ineffective or results in more crime.

Lastly, the motivation to efficiently implement plans might narrow focus in an important way for those people charged with crafting policies. According to mindset theory, when people are pursuing a goal, there are four crucial phases: a phase in which people deliberate and choose between potential goals, a phase in which people plan how to implement their chosen goal, a phase in which people act on the plan, and a phase in which people evaluate how the plan went (Gollwitzer, 1990, 2003). While a motivation to deliberate carefully between goals might be very useful during the first phase, a deliberative mindset can sometimes be detrimental while planning implementations, because it can slow down planning efficiency. Thus, the motivation to deliberate seems to dissipate during the second phase when planning becomes important, and the result is a corresponding shift in cognitive focus. The deliberative mindset fosters relatively accurate appraisals of evidence, but the implemental mindset fosters a biased focus on feasibility and desirability-related information in order to help enact plans efficiently. As a result, people in an implemental mindset are typically much more optimistic about the outcomes of their plans than people in a deliberative mindset. They report strong illusions of control over uncontrollable outcomes and a host of other optimistic biases. Once prohibitionists identified reducing alcohol consumption as an important goal, they probably exited the deliberative mindset and became focused on implementing a plan to do so. The motivation to achieve their goal by implementing plans effectively and efficiently might have narrowed their focus to only consider information relevant to why their proposed plan was feasible or desirable. This narrowed focus would have caused them to fail to carefully deliberate over evidence relevant to the potential unintended consequences of their actions.

\section{Cognitive Bias and the Failure to Anticipate}

Above and beyond the ways in which one's preferences might cloud predictions, dispassionate cognitive biases can also contribute to the failure to foresee unintended consequences even when people do not possess a strong desire to uphold a particular belief. When making judgments, people tend to think about complicated systems in overly simplistic terms, focusing on a few salient features of a decision instead of the entirety of the complexity of the system. An abundance of research demonstrates that the features of a choice that happen to be most salient or focal at the time of judgment will receive disproportionate weight (e.g., Buehler \& Griffin, 2003; Klar \& Giladi, 1999; Kruger \& Burrus, 2004; Taylor \& Fiske, 1975; Windschitl, Kruger, \& Simms, 2003), a phenomenon referred to as focalism (e.g., Kahneman, Slovic, \& Tversky, 1982; Koehler, 1991; Schwarz, 1990). Decision-makers do not seem to exhibit a natural tendency to adopt a broad focus when making judgments and they often neglect relevant information even in the absence of motivation to do so. Instead, judgments are strongly affected, and often led astray, by factors that are continuously focal, such as one's current thoughts and feelings (e.g., Dunning \& Hayes, 1996; Gilovich, Medvec, and Savitsky, 2000; Gilovich, Savitsky, \& Medvec, 1998; Keysar, Barr, Balin, \& Brauner, 2000; Kruger, 1999).

One powerful example of the effects of narrowed focus demonstrates that judgments of happiness are influenced by whatever aspect of life is most accessible in one's mind when 
the judgment is made. Responses to the questions "How happy are you?" and "How many dates did you have in the last month?" tend not to correlate if the questions are asked in this order. If, however, participants are asked about dating first, responses to the two questions are very strongly correlated (Schwarz \& Strack, 1999). Focused on their success (or lack thereof) in dating, participants gave little weight to the presence of friends, family and all of the other factors that might otherwise be relevant for assessing happiness.

Tversky (1977) provided a seminal illustration of how focus can bias judgment. He asked participants to choose whether East and West Germany were more similar than were Nepal and Ceylon. Because East and West Germany were better known to participants, they were able to more easily think of similarities between these countries than for Nepal and Ceylon. As a result, most participants chose East and West Germany as the most similar set. However, a second group was asked which set of countries was more dissimilar and most chose East and West Germany. The questions were logically equivalent, but those asked about similarity focused on similarities while those asked about dissimilarity focused on differences. Because participants answered the question by relying on a subset of their knowledge about the countries, the groups gave contradictory responses.

This focalism bias leads people to offer judgments and predictions that are based too much on information that is most focal (e.g., one's current thoughts and feelings) and too little on information that is less focal, across a variety of judgment types and domains (e.g., Dunning \& Hayes, 1996; Kahneman, Slovic, \& Tversky, 1982; Keysar, Barr, Balin, \& Brauner, 2000; Koehler, 1991). Several lines of recent research suggest that focalism also contributes to a failure to accurately anticipate unintended consequences. First, research on economic game playing has demonstrated that focalism might cause people to fail to anticipate one particular type of secondary consequence - those that stem from interactions with competitors. Tor and Bazerman (2003) observed that when playing economic games, people focus on the intended effects of their own actions in isolation, rarely considering the important ways their actions might interact with the decisions that their competitors are making. They perform poorly as a result.

In addition, Ehrlinger and Eibach (2011) have argued that focalism should lead to a failure to anticipate unintended consequences in a broad range of circumstances. One would expect that because intended consequences represent the primary purpose of undertaking an action, they are the most likely to capture people's narrow focus. For example, Ehrlinger (2004) asked participants to shoot basketball free throws first individually and then in a group. When participants made predictions regarding the final score, they narrowly focused on the intended effect of a higher basketball score by virtue of joining together as a team. However, when shooting in a group they were also likely to run into coordination problems such as getting in each other's way. Those who failed to focus on the possibility of these coordination issues made overconfident predictions of the team score. In this laboratory scenario, there is no reason to think that participants would have felt passionately motivated to imagine that the group version of the task would lead to greater success. Thus, as Ehrlinger and Eibach argue, even in the absence of a motivation to ignore the unwanted consequences of an action, people might still narrowly focus on intended consequences simply because intended consequences come to mind most easily and decision-makers seem inclined to adopt a narrow focus.

Beyond the initial problem of needing to broaden people's narrow focus to include a consideration of unintended consequences, research on anchoring and adjustment suggests that even dispassionate decision-makers who attempt to focus on unanticipated consequences might underweight their importance. When faced with having to make predictions under conditions of uncertainty, individuals tend to begin with what they 
already know and use that as an anchor for judgment. Known features of the problem, including one's intentions and desired consequences, are relatively easy to think about and come to mind quite quickly. In this way, intended consequences provide an anchor point for predictions and from which individuals must adjust. Previous research suggests that when people anchor their judgments on an initial starting point and then attempt to make adjustments as necessary, adjustments of this sort are usually insufficient, resulting in predictions that are too close to the initial anchor (Epley \& Gilovich, 2001; Kahneman, Slovic, \& Tversky, 1982; Tversky \& Kahneman, 1974). Typically, the adjustments are thought to be insufficient because they are cognitively effortful, as evidenced by the fact that introducing cognitive busyness results in judgments even closer to the initial anchor value for self (Cervone \& Peake, 1986) and social judgment (Gilbert \& Osborne, 1989), as well as for estimates of probability (Plous, 1989). We argue that in the rare cases that individuals recognize that unintended consequences are possible, anchoring first on the intended effects of their actions is likely to result in predictions that still overweight the possibility of the intended and underweight the possibility of the unintended consequences. We should note that these predictions are likely to be much more accurate than were people to not attempt to adjust for unintended consequences. However, they will probably still fail to properly account for the possibility of all complex side effects an action.

Ehrlinger (2004) conducted research to directly test the hypothesis that participants who were cognitively busy were less likely to anticipate unintended consequences than those who were not. In one study, Ehrlinger used the real world example of the development of the Homeland Security Act, an action that had the explicit goal of reducing the threat of terrorism on American soil, but that experts thought could result in many negative unintended consequences. Participants were asked to predict the effect of the Homeland Security act on a series of personal, national, and international dimensions either naturally or while cognitively occupied with the task of counting the number of times their eyes blinked. As predicted, cognitively busy participants were more confident that the Act would result in the intended consequences than were control participants. Cognitively busy participants were less likely to mention potential unintended consequences and, consequently, offered more positive estimates of the net effect of the Act. These findings suggest that people anchored their predictions on the stated intended consequences of the Act and then engaged in effortful adjustments of those predictions when they had the cognitive resources available to do so. In a second study, participants were randomly assigned to either a cognitively busy or control condition and then asked to predict the consequences of a recently introduced postSeptember $11^{\text {th }}$ reform, the Color-Coded Terror Alert System. As one might expect, cognitively busy participants listed fewer potential consequences of any type than did control participants. Beyond this simple tendency to list less information, cognitively busy participants were less likely than control participants to mention potential unintended consequences of the Terror Alert system, in particular. Together, this research suggests that one strategy for improving the consideration of unintended consequences might be to remove cognitive distractions that could hinder people's ability to adjust from their initial predictions, given that those initial predictions might be likely to be anchored by the intended consequences of actions.

A bias toward hypothesis confirmation is likely to also contribute to a failure to anticipate unintended consequences. People tend to have a confirmation bias, or a tendency to search for or focus on information that could confirm an initial hypothesis more than information that might disconfirm that hypothesis. In the same way that the intended con- 
sequence of an action might represent an anchor point from which people fail to sufficiently adjust, the intended consequence of an action is likely to serve as an initial hypothesis regarding what consequences that action will have. The confirmation bias can be distinguished from motivated reasoning, in that the preference for confirmatory information does not have to be driven by a motivated desire to confirm the hypothesis. Instead, this bias exists in the strategies that people use to test hypotheses by preferentially seeking out confirming information (for a review, see Klayman \& Ha, 1987). For example, imagine that a city decides to paint crosswalks at several busy intersections in an effort to improve pedestrian safety. In wondering whether this policy has led to its intended consequence, people might more often ask questions that could confirm the initial hypothesis that painting crosswalks will improve pedestrian safety than questions that might disconfirm this hypothesis. In this example, a confirmation bias would lead people to attend too much to instances in which pedestrians were able to safely traverse busy intersections with newly painted crosswalks. To truly understand whether crosswalks improve pedestrian safety, however, people would have to ask for information that is often ignored, regarding instances that pedestrians safely cross intersections without crosswalks, and information about the number of pedestrian accidents at intersections with and without newly painted crosswalks. This tendency to narrowly focus attention on confirmatory information is likely to contribute to a focus on the intended consequences of an action and impair people's ability to foresee unintended consequences. Once people look at all of the relevant information regarding the impact of crosswalks on pedestrian safety, it becomes clear that crosswalks do not always improve pedestrian safety. Indeed, in at least some cases, crosswalks increase the likelihood of an accident. The knowledge that cars are required to stop at crosswalks leaves pedestrians with a false sense of security that has increased their carelessness (Purdum, 1997; Surface Transportation Policy Project, 2000).

To this point, we have made a clear distinction between the impact of preferences or motivation on the consideration of potential unintended consequences and the impact of cognitive bias. However, motives can often serve to exacerbate cognitive biases in judgment. We suspect that this intersection between motivation and cognition is common when considering the consequences of policy decisions. Indeed, it might be rare that people do not have strong preferences and motives regarding the outcome of policy decisions and these motives might make it particularly difficult to maintain the broad focus necessary to foresee unintended consequences.

Several lines of research support the idea that preferences for an intended consequence might exacerbate cognitive focal biases. For example, the "planning fallacy" refers to the idea that people tend to confidently believe that their own projects and plans will proceed on schedule without any problems, even though they know that many similar projects have run late (Kahneman \& Tversky, 1979). Kahneman and Tversky suggested that when people predict how well a task will go and how quickly it will be completed, they can utilize singular information (information and mental simulations related to the specific properties of the singular upcoming task being considered) and distributional information (information related to how long other similar tasks took to complete). Typically, people who adopt a distributional focus make more accurate predictions, and the planning fallacy is thought to result from a narrowed focus on singular information. Buehler, Griffin, and MacDonald (1997) demonstrated that the kind of focalism that leads to the planning fallacy might in part be triggered by the motivation to believe one's plans will be completed quickly. In one field experiment, individuals expecting a tax refund predicted they would be able to complete their tax return about 10 days earlier than people who were expecting to owe money. Interestingly, the motivation to complete the tax return quickly appeared to enhance the 
planning fallacy by amplifying focal biases. Individuals who made optimistic predictions appeared to do so because they focused less on the time taken to complete previous tax returns. Thus, a desire to complete a task in a timely fashion can trigger a narrowed focus on singular information and result in overly optimistic predictions. This line of work provides an excellent example of how desire and motivation can trigger cognitive focal biases that might cause people to neglect information relevant to what they do not intend.

\section{How to Improve Anticipation of Unintended Consequences}

This analysis of the psychological forces that prevent people from anticipating unintended consequences can potentially be used to improve to their anticipation. Dawson, Gilovich, and Regan (2002) argued that if people can become motivated to reject a proposal, they will skeptically search the proposal for problems and become less susceptible to the reasoning errors that come into play when only motivated to see the proposal's benefits. These researchers subjected participants to a common logic and reasoning task known as the Wason selection task, in which the appropriate strategy is to search for disconfirmation of a given rule. They successfully manipulated participants' motivation to either confirm or disconfirm the rule and discovered that participants motivated to disconfirm the rule performed better on the task that those who were motivated to confirm it. Thus, attempting to manipulate people's motivations to consider an action's drawbacks should increase the accuracy with which the potential drawbacks are perceived. In addition, this research suggests that if people consult with other decision-makers who are motivated to skeptically consider their proposals, doing so will help them anticipate the unintended consequences of their actions more accurately. Janis has argued that when policy-making groups work together to solve problems, if all the members are motivated to see a particular action confirmed, they should bring in outside experts who might have motivations contrary to that of the group (Janis, 1972, 1982; Janis \& Mann, 1977).

When motivational factors are not the only source of the problem, one can also manipulate attention in a way that reduces the impact of focalism and improves anticipation. In an attempt to manipulate attentional focus in the domain of unintended consequences, Ehrlinger and Eibach (2011) had participants make predictions about the future consequences of certain spending proposals after they engaged in a "defocusing" exercise that encouraged them to consider the larger system of variables. Participants in the "defocused" condition were asked to indicate how much money each national spending category should ideally receive in terms of percentages of the total budget as opposed to absolute dollars, forcing them to pay attention to how increasing or decreasing spending in one category might have the unintended effect of increasing or decreasing the budget for other unrelated programs. Compared to the control condition, participants in the defocused condition rated the potential overall outcome of the proposals as less positive. The degree to which participants considered the unintended consequences of the proposal was shown to mediate the effect of the defocusing condition on their positivity ratings. Taken together, this work suggests that very subtle manipulations of attentional focus can have a large impact on the degree to which decision-makers suffer from the kind of extreme focalism that limits their ability to anticipate the future unintended consequences of their actions.

\section{Concluding Thoughts}

Policy decisions can lead to a host of unanticipated and unintended consequences. The world is inherently complex and chaotic, and, as such, decision-makers are often unable 
to consider everything necessary to properly anticipate unintended consequences of their actions. However, above and beyond the simple difficulty of knowing all that might be necessary to properly anticipate unintended consequences, the present review provides evidence that several psychological biases contribute to the likelihood that people will fail to foresee unintended consequences. Specifically, a motivation to believe that the intended consequence will come to pass combined with a cognitive tendency to place too much focus and weight on the intended consequence, and too little on alternative. Consequences, make it particularly difficult to anticipate unintended consequences. In addition to a better understanding of why people fail to foresee unintended consequences, this analysis offers specific conclusions about how to improve the likelihood of anticipation. To limit the degree to which motivated reasoning might limit the ability to foresee unintended consequences decision-makers should consult with and, importantly, listen carefully to people whose motivations differ from their own. In addition, decision makers should recognize that people tend to focus too narrowly on what is intended and engage in exercises designed to highlight the full system of interconnected variables in which the proposed change exists. They should take care to consider how the proposed policy might impact other variables within this system and to do so in an environment in which their cognitive resources are not taxed. By attending to the lessons that people have learned about the potential for unintended consequences in specific cases relevant to their decision, and to the more general lessons about psychological factors that can limit the ability to foresee unintended consequences, decision makers should improve their chances of foreseeing potentially unintended and unanticipated consequences of policies and, ultimately, make well-informed, well-considered decisions.

\section{Short Biographies}

Erin Sparks' research examines biases in social judgment and the impact of maximizing on commitment to and satisfaction with one's choices. She earned her BA from the University of Chicago. She is currently a doctoral student in Psychology at Florida State University, where she earned her Masters in Psychology.

Joyce Ehrlinger's research focuses on understanding the sources of error and accuracy in self and social judgment. For example, Dr. Ehrlinger has examined how self-beliefs regarding ability and regarding the malleability of attributes impact behavior in achievement situations and perceptions of performance. She has also examined how naïve realism leads people to perceive their own views as better informed and less biased than those of others and, in turn, leads to overconfident perceptions of the ease of persuading others. Her work has been feature in a broad range of journals including the Journal of Personality and Social Psychology, the Journal of Experimental Social Psychology, and Personality and Social Psychology Bulletin and has been covered in the popular media. She earned her BA at Bowling Green State University and $\mathrm{PhD}$ at Cornell University. After completing a postdoctoral position at Stanford University, Dr. Ehrlinger moved to her current position as assistant professor of psychology at Florida State University. For more information, go to http://www.psy.fsu.edu/ ehrlinger/.

\section{Endnote}

^ Correspondence address: 1107 West Call Street, Tallahassee, FL 32306-4301, USA. Email: ehrlinger@psy.fsu.edu 


\section{References}

Buehler, R., \& Griffin, D. (2003). Planning, personality, and prediction: The role of future focus in optimistic time predictions. Organizational Behavior and Human Decision Processes, 92, 80-90.

Buehler, R., Griffin, D., \& MacDonald, H. (1997). The role of motivated reasoning in optimistic time predictions. Personality \& Social Psychology Bulletin, 23, 238-247.

Cervone, D., \& Peake, P. K. (1986). Anchoring, efficacy, and action: The influence of judgmental heuristics on self-efficacy judgments and behavior. Journal of Personality and Social Psychology, 50, 492-501.

Cohen, G. (2003). Party over policy: The dominating impact of group influence on political beliefs. Journal of Personality and Social Psychology, 85, 808-822.

Dawson, E., Gilovich, T., \& Regan, D. T. (2002). Motivated reasoning and performance on the Wason selection task. Personality and Social Psychology Bulletin, 28, 1379-1387.

Ditto, P. H., Scepansky, J. A., Munro, G. D., Apanovitch, A. M., \& Lockhart, L. K. (1998). Motivated sensitivity to preference-inconsistent information. Journal of Personality and Social Psychology, 75, 53-69.

Dunning, D., \& Hayes, A. F. (1996). Evidence for egocentric comparison in social judgment. Journal of Personality and Social Psychology, 71, 213-229.

Ehrlinger, J. (2004). Complexity neglect: Psychological sources of the failure to anticipate unintended consequences (Doctoral Dissertation, Cornell University). Dissertational Abstracts International, 65, 3551B.

Ehrlinger, J., \& Eibach, R. P. (2011). Focalism and the failure to foresee unintended consequences. Basic and Applied Psychology, 33, 59-68.

Epley, N., \& Gilovich, T. (2001). Putting adjustment back in the anchoring and adjustment: Differential processing of self-generated and experimenter-provided anchors. Psychological Science, 12, 391-396.

Fisher, E. S., \& Welch, H. G. (1999). Avoiding the unintended consequences of growth in medical care: How might more be worse? Journal of the American Medical Association, 281, 446-453.

Gilbert, D. T., \& Osborne, R. E. (1989). Thinking backward: Some curable and incurable consequences of cognitive busyness. Journal of Personality and Social Psychology, 57, 940-949.

Gilovich, T. (1991). How We Know What Isn't So: The Fallibility of Human Reason in Everyday Life. New York: The Free Press.

Gilovich, T., Medvec, V. H., \& Savitsky, K. (2000). The spotlight effect in social judgment: An egocentric bias in estimates of the salience of one's own actions and appearance. Journal of Personality and Social Psychology, 78, 211222.

Gilovich, T., Savitsky, K., \& Medvec, V. H. (1998). The illusion of transparency: Biased assessments of others' ability to read our emotional states. Journal of Personality and Social Psychology, 75, 332-346.

Gollwitzer, P. M. (1990). Action phases and mind-sets. In E. T. Higgins \& R. M. Sorrentino (Eds.), Handbook of Motivation and Cognition: Foundations of Social Behavior (Vol. 2, pp. 53-92). New York: Guilford Press.

Gollwitzer, P. M. (2003). Why we thought that action mind-sets affect illusions of control. Psychological Inquiry, 14, $259-267$.

Gulas, C. S., \& McKeage, K. (2000). Extending social comparison: An examination of the unintended consequences of idealized advertising imagery. Journal of Advertising, 29, 17-28.

Janis, I. (1972). Victims of Groupthink: A Psychological Study of Foreign Policy Decisions and Fiascoes. Boston: Houghton Mifflin Company.

Janis, I. (1982). Groupthink: A Psychological Study of Policy Decisions and Fiascoes. Boston: Houghton Mifflin Company.

Janis, I., \& Mann, L. (1977). Decision Making: A Psychological Analysis of Conflict, Choice, and Commitment. New York, NY: Free Press.

Kahneman, D., Slovic, P., \& Tversky, A. (1982). Judgment under Uncertainty: Heuristics and Biases. NY: Cambridge Press.

Kahneman, D., \& Tversky, A. (1979). Intuitive prediction: Biases and corrective procedures. TIMS Studies in Management Science, 12, 313-327.

Kaminski, M. (2001). Unintended consequences: Organizational practices and their impact on workplace safety and productivity. Journal of Occupational Health Psychology, 6, 127-138.

Keysar, B., Barr, D. J., Balin, J. A., \& Brauner, J. S. (2000). Taking perspective in conversation: The role of mutual knowledge in conversation. Psychological Science, 11, 32-38.

Kipnis, D. (1993). Unanticipated consequences of using behavior technology. Leadership Quality, 4, $149-171$.

Klar, Y., \& Giladi, E. E. (1999). Are most people happier than their peers, or are they just happy? Personality and Social Psychology Bulletin, 25, 585-594.

Klayman, J., \& Ha, Y. (1987). Confirmation, disconfirmation, and information in hypothesis testing. Psychological Review, 94(2), 211-228.

Koehler, D. J. (1991). Explanation, imagination, and confidence in judgment. Psychological Bulletin, 110, $499-519$.

Kruger, J. (1999). Lake Wobegon be gone! The "below-average effect" and the egocentric nature of comparative ability judgments. Journal of Personality and Social Psychology, 77, 221-232. 
Kruger, J., \& Burrus, J. (2004). Egocentrism and focalism in unrealistic optimism (and pessimism). Journal of Experimental Social Psychology, 40, 332-340.

Kunda, Z. (1987). Motivation and inference: Self-serving generation and evaluation of evidence. Journal of Personality and Social Psychology, 53, 636-647.

Kunda, Z. (1990). The case for motivated reasoning. Psychological Bulletin, 108, 480-498.

Levine, M. (1980). A potential unanticipated consequence of legislation to protect human subjects. American Psychologist, 35, 583-584.

Lord, C. G., Ross, L., \& Lepper, M. R. (1979). Biased assimilation and attitude polarization: The effects of prior theories on subsequently considered evidence. Journal of Personality and Social Psychology, 37, 2098-2109.

McBriarty, M. A. (1988). Performance appraisal: Some unintended consequences. Public Personnel Management, 17, 421-434.

Meddin, B. (1986). Unanticipated and unintended consequences of the group process: Enhancing successful group functioning. Social Work with Groups, 9, 83-92.

Nyhan, B. (2010). Why the "death panel" myth wouldn't die: Misinformation in the health care reform debate. The Forum, 8, 5.

Ohland, G., Nguyen, T., \& Corless, J. (2000). Dangerous by Design: Pedestrian Safety in California. Sacramento, CA: Surface Transportation Policy Project.

Opp, K. D. (2002). When do norms emerge by human design and when by the unintended consequences of human action? The example of the no smoking norm. Rationality and Society, 14, 131-158.

Oyer, P., \& Schaeffer, S. (Summer 2003). The unintended consequences of the '91 civil rights act. Regulation, 26, 42-47.

Plous, S. (1989). Thinking the unthinkable: The effects of anchoring on likelihood estimates of nuclear war. Journal of Applied Social Psychology, 19, 67-91.

Pratto, F., \& John, O. P. (1991). Automatic vigilance: The attention-grabbing power of negative social information. Journal of Personality and Social Psychology, 61, 380-391.

Purdum, T. S. (1997). Pedestrians and drivers square off on crosswalks. New York Times. August 25.

Reason, J. T. (1987). The Chernobyl errors. Bulletin of the British Psychological Society, 40, 201-206.

Ross, M., McFarland, C., \& Fletcher, G. J. O. (1981). The effect of attitude on the recall of personal histories. Journal of Personality and Social Psychology, 40, 627-634.

Sanitioso, R., Kunda, Z., \& Fong, G. T. (1990). Motivated recruitment of autobiographical memory. Journal of Personality and Social Psychology, 59, 229-241.

Sarason, S. B. (1978). An unsuccessful war on poverty? American Psychologist, 33, 831-839.

Schwarz, N. (1990). Feelings as information: Informational and motivational functions of affective states. In R. Sorrentino \& E. T. Higgins (Eds.), Handbook of Motivation and Cognition (Vol 2., pp. 527-561). New York: Guilford Press.

Schwarz, N., \& Strack, F. (1999). Reports of subjective well-being: Judgmental processes and their methodological implications. In D. Kahneman, E. Diener \& N. Schwarz (Eds.), Well-being: The Foundations of Hedonic Psychology (pp. 61-84). New York: Russel Sage Foundation.

Taylor, S. E. (1991). The asymmetrical impact of positive and negative events: The mobilization-minimization hypothesis. Psychological Bulletin, 110, 67-85.

Taylor, S. E., \& Fiske, S. T. (1975). Point of view and perceptions of causality. Journal of Personality and Social Psychology, 32, 439-445.

Thornton, M. (1998). The potency of illegal drugs. Journal of Drug Issues, 28, 725-740.

Tor, A., \& Bazerman, M. H. (2003). Focusing failures in competitive environments: Explaining decision errors in the Monty Hall Game, the acquiring a company problem, and multiparty ultimatum. Journal of Behavioral Decision Making, 16, 353-374.

Tversky, A. (1977). Features of similarity. Psychological Review, 84, 327-352.

Tversky, A., \& Kahneman, D. (1974). Judgment under uncertainty: Heuristics and biases. Science, 185, 1124-1130.

Wilson, D., Hickson, D. J., \& Miller, S. J. (1999). Decision overreach as a reason for failure: How organizations can overbalance. In H. K. Anheier (Ed.) When things go wrong: Organizational failures and breakdowns. (pp. 35-49). Thousand Oaks, CA: Sage Publications, Inc.

Windschitl, P. D., Kruger, J., \& Simms, E. N. (2003). The influence of egocentrism and focalism on people's optimism in competitions: When what affects us equally affects me more. Journal of Personality and Social Psychology, 85, 389-408. 